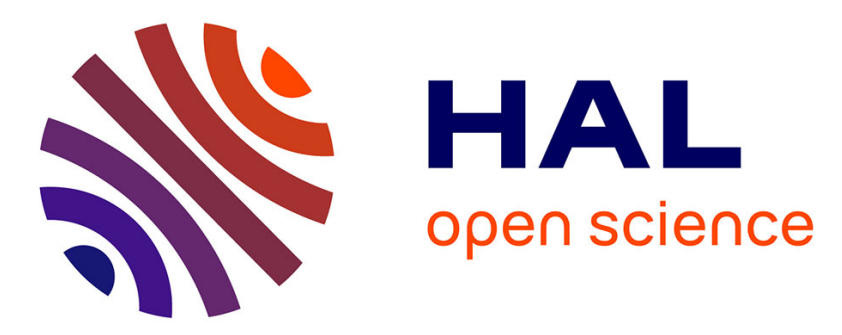

\title{
Inelastic Interface Damage Modeling with Friction Effects: Application to Z-Pinning Reinforcement in Carbon Fibre Epoxy Matrix Laminates
}

Laurent Gornet, Hassan Ijaz, Denis Cartié

\section{- To cite this version:}

Laurent Gornet, Hassan Ijaz, Denis Cartié. Inelastic Interface Damage Modeling with Friction Effects: Application to Z-Pinning Reinforcement in Carbon Fibre Epoxy Matrix Laminates. Journal of Composite Materials, 2010, 44 (17), pp.2067-2081. 10.1177/0021998309359214 . hal-01006965

\section{HAL Id: hal-01006965 \\ https://hal.science/hal-01006965}

Submitted on 11 Oct 2017

HAL is a multi-disciplinary open access archive for the deposit and dissemination of scientific research documents, whether they are published or not. The documents may come from teaching and research institutions in France or abroad, or from public or private research centers.
L'archive ouverte pluridisciplinaire HAL, est destinée au dépôt et à la diffusion de documents scientifiques de niveau recherche, publiés ou non, émanant des établissements d'enseignement et de recherche français ou étrangers, des laboratoires publics ou privés. 


\title{
Inelastic Interface Damage Modeling with Friction Effects: Application to Z-Pinning Reinforcement in Carbon Fiber Epoxy Matrix Laminates
}

\author{
LAURENT GORNET AND HASSAN IJAZ* \\ GeM-UMR-CNRS 6183, Ecole Centrale de Nantes - 1 Rue de la Noë \\ BP 92101, 44321 Nantes Cedex 3, France \\ DENIS D. R. CARTIÉ \\ Composites Centre, Department of Materials, Cranfield University, MK43 OAL, UK
}

\begin{abstract}
This article presents the implementation of a new inelastic damage model able to carry out simulation of initiation and evolution of damage in the Z-pinned laminated composite structures with friction effects. The classical elastic damage model is modified to an inelastic model with friction effects obeying the simple Coulomb friction criterion. The main idea is the modification of strain energy parameter by introducing sliding and friction parameters. The simulations of single Z-fiber pull tests highlight the effectiveness of the proposed model for micro-scale predictions.
\end{abstract}

KEY WORDS: fiber reinforced materials, damage mechanics, finite element analysis, cohesive zone modeling.

\section{INTRODUCTION}

$\mathbf{F}$ OR WEIGHT SAVING purposes, the use of composite materials is no longer limited to secondary structure, but is expanding to primary load-bearing structures. The design can be tailored to the application by careful optimization of the fiber orientations. However, with the increasing use of composites in aircrafts, trains, and ships there is a need for improved damage models for better prediction of the long-term behavior of the composite structures. Due to their laminated nature, composite materials are prone to interlaminar cracking called delamination. This phenomenon can be initiated by edge

\footnotetext{
*Author to whom correspondence should be addressed. E-mail: hassan605@yahoo.com
} 
effects, manufacturing defects, and impacts. Delaminations can cause dramatic reduction of the load-carrying capability of the material.

The fracture process of high performance composite laminates is complex, involving not only interlaminar damage (delamination), but also intralaminar damage mechanisms like matrix cracking and fibre fracture. A lot of work has been carried out at the meso-scale (layers and interfaces) to understand the delamination failure process by Allix et al. [1-4], Corigliano and Allix [5] Corigliano [6], Gornet [7], Alfano and Crisfield [8], and Boutaous et al. [9]. In order to improve the toughness of the laminated composites against the delamination crack propagation, a successful approach is defined by introducing Z-fibers in the laminates [10,11].

Meso-scale, which lies between the micro and macro scale, consists of two basic constituents: layers and interfaces. The interlaminar interface is a 2D mechanical surface that connects two adjacent layers. The mechanical properties of interface depend on the relative orientation of fibers of adjacent layers. For practical applications, a key feature has been to implement a cohesive zone model, in which interface debonding process is combined with friction effects. Tvergaard [12] introduced the concept of using friction only after complete debonding, therefore no friction during the interface debonding process. Alfano and Sacco [13] has combined interface damage and friction in a cohesive zone model. His strategy is based on the idea of taking representative elementary area (REA), which consists of damaged part and undamaged part, whereas friction effect has been included in damaged part. Alfano used bilinear damage evolution behavior. $\mathrm{He}$ used this law to simulate the push-out test and mainly to simulate the behavior of a brick wall structure in civil engineering [13]. A simple damage model proposed by Needleman [14] was extended by Chaboche et al. [15,16] with the introduction of the friction effects in the cohesive zone, which after complete debonding behaves like contact/friction. In his approach, the damage evolution is function of relative displacement at the interface. In this article, a cohesive zone model with friction effects is proposed. This model is an extension of elastic damage model presented by Allix et al. [1-4] with the concept of improved strain energy criterion by introducing sliding and friction effects [15]. The damage evolution law proposed here is a function of equivalent damage energy release rate of the interface, where as for most of the other models available in literature, damage evolution is a function of relative interfacial displacement. Similar to the model developed by Chaboche, the equations of the proposed model are derived in thermodynamic framework [17]. Delay effect regularization can also be incorporated to further modify proposed model easily [7,18]. A simulation of a Z-fiber T300/ BMI pull-out test from laminate IMS/924, which corresponds to mode II interface test, is performed in finite element code Cast3M (CEA) [19] for proposed inelastic damage model including friction effects. At the end, results are compared with available experimental data [20].

The article is organized as follows: in the section 'Interface Modeling,' basics of elastic damage mechanics are recalled. In the section 'Inelastic Damage Model with Friction,' inelastic damage model with friction effects is presented in detail. In the section 'Influence of Interfacial Parameters on Interface Behavior,' effects of different interfacial parameters on damage evolution for the proposed model are shown through graphical representations. In the section 'Pull-out Test,' finite element simulations in Cast3M for Z-fiber pull-out from laminate are performed and resulting graphs are compared with available experimental data. Finally, concluding remarks are given in the final section. 


\section{INTERFACE MODELING}

The interface is a surface entity, which ensures the transfer of stress and displacement between two adjacent layers as shown in Figure 1. This modeling coupled with damage mechanics makes it possible to take into account the phenomenon of delamination that can occur during the mechanical loading of structural parts. The relative displacement of one layer to other layer can be written as:

$$
U=[U]=U^{+}-U^{-}=U_{1} N_{1}+U_{2} N_{2}+U_{3} N_{3}
$$

where $N_{1}, N_{2}$, and $N_{3}$ represents the orthogonal directions of the interface modeling. The deformation/strain energy of damaged material can be written as follows [1-4]:

$$
E_{D}=\frac{1}{2}\left[\frac{\left\langle\sigma_{33}\right\rangle_{-}^{2}}{k_{3}}+\frac{\left\langle\sigma_{33}\right\rangle_{+}^{2}}{k_{3}\left(1-d_{3}\right)}+\frac{\sigma_{23}^{2}}{k_{2}\left(1-d_{2}\right)}+\frac{\sigma_{13}^{2}}{k_{1}\left(1-d_{1}\right)}\right]
$$

where $\langle x\rangle_{+}$and $\langle x\rangle_{-}$represents the positive and negative parts of $x$, respectively. The above-mentioned strain energy criteria has been successfully applied to finite element simulations of double cantilever beam (DCB), end notched flexure (ENF), and mixed mode bending (MMB) specimens [7]. The deterioration of the interface is taken into account by three internal damage variables $\left(d_{1}, d_{2}\right.$, and $\left.d_{3}\right)$. It is supposed that there will be no damage at the interface in compression. Here, $k_{1}, k_{2}$, and $k_{3}$ are interface rigidities associated to the damage variables in orthogonal directions.

The relation between the stress and the displacement is written in the orthotropic axis of the interface as:

$$
\left(\begin{array}{l}
\sigma_{13} \\
\sigma_{23} \\
\sigma_{33}
\end{array}\right)=\left(\begin{array}{ccc}
k_{1}\left(1-d_{1}\right) & 0 & 0 \\
0 & k_{2}\left(1-d_{2}\right) & 0 \\
0 & 0 & k_{3}\left(1-d_{3}\right)
\end{array}\right)\left(\begin{array}{c}
U_{1} \\
U_{2} \\
U_{3}
\end{array}\right) .
$$

The thermodynamic model is built by taking into account of the three possible modes of delamination. Three different damage variables can be distinguished according to three modes of failure. The three thermodynamic forces associated to the damage variables are:

$$
Y_{d_{3}}=\frac{1}{2} \frac{\left\langle\sigma_{33}\right\rangle_{+}^{2}}{k_{3}\left(1-d_{3}\right)^{2}}, \quad Y_{d_{1}}=\frac{1}{2} \frac{\sigma_{13}^{2}}{k_{1}\left(1-d_{1}\right)^{2}}, \quad Y_{d_{2}}=\frac{1}{2} \frac{\sigma_{23}^{2}}{k_{2}\left(1-d_{2}\right)^{2}} .
$$

The energy dissipated in this model can be expressed as:

$$
\Phi=Y_{d_{1}} \dot{d}_{1}+Y_{d_{2}} \dot{d}_{2}+Y_{d_{3}} \dot{d}_{3} \quad(\Phi \geq 0) .
$$

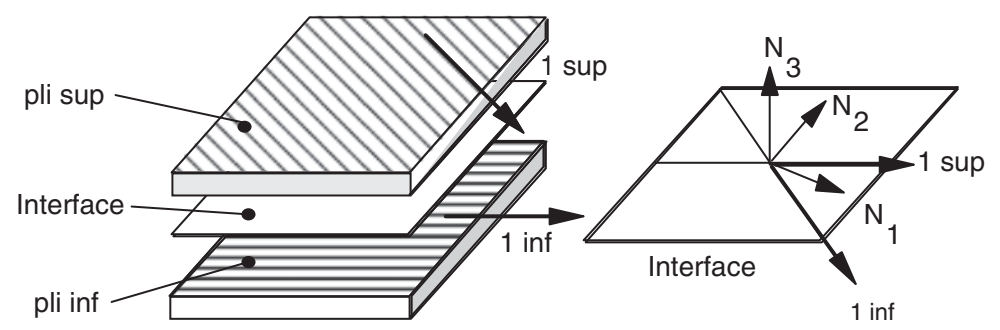

Figure 1. Interface between plies. 
It is supposed that the three different damage variables corresponding to three modes of failures are very strongly coupled and are governed by equivalent strain energy release rate function as follows:

$$
\underline{Y}(t)=\left.\max \right|_{\tau \leq t}\left(\left(\left(Y_{d_{3}}\right)^{\alpha}+\left(\gamma_{1} Y_{d_{1}}\right)^{\alpha}+\left(\gamma_{2} Y_{d_{2}}\right)^{\alpha}\right)^{1 / \alpha}\right),
$$

where $\gamma_{1}$ and $\gamma_{2}$ are coupling parameters and $\alpha$ is a material parameter, which governs the damage evolution in mixed mode. The damage evolution law is then defined by the choice of a material function as follows:

$$
\begin{aligned}
& \text { if }\left[\left(d_{3}<1\right) \text { and }\left(\underline{Y}<Y_{R}\right)\right] \\
& \text { then } \\
& \qquad d_{1}=d_{2}=d_{3}=\omega(\underline{Y}) \\
& \text { else } \\
& \qquad d_{1}=d_{2}=d_{3}=1 .
\end{aligned}
$$

The damage function is selected in the form:

$$
\omega(\underline{Y})=\left[\frac{n}{n+1} \frac{\left\langle\underline{Y}-Y_{O}\right\rangle_{+}}{Y_{C}-Y_{O}}\right]^{n},
$$

where $Y_{O}$ is the threshold damage energy, $Y_{C}$ is the critical damage energy, $n$ is the characteristic function of material, higher values of $n$ correspond to brittle interface, and $Y_{R}$ is the energy corresponding to rupture, $Y_{R}=Y_{O}+((n+1) / n) d^{1 / n}\left(Y_{C}-Y_{O}\right)$.

A simple way to identify the propagation parameters is to compare the mechanical dissipation yielded by two approaches of damage mechanics and linear elastic fracture mechanics (LEFM). In the case of pure mode situations, when the critical energy release rate reaches its stabilized value at the propagation denoted by $G_{C}$ :

$$
G_{I C}=Y_{C} ; G_{I I C}=\frac{Y_{C}}{\gamma_{1}} ; G_{I I I C}=\frac{Y_{C}}{\gamma_{2}} .
$$

And for mixed-mode loading situation, a standard LEFM model is defined as:

$$
\left(\frac{G_{I}}{G_{I C}}\right)^{\alpha}+\left(\frac{G_{I I}}{G_{I I C}}\right)^{\alpha}+\left(\frac{G_{I I I}}{G_{I I I_{C}}}\right)^{\alpha}=1 .
$$

In a general mixed-mode debonding process, the global fracture energy can be computed as follows:

$$
G_{C T}=G_{I}+G_{I I}+G_{I I I}
$$

A typical response of this model is given in Figure 2 for pure mode I.

\section{INELASTIC DAMAGE MODEL WITH FRICTION}

The model proposed here is based on the strain energy criterion which includes the friction and slip effects [15]. The model proposed by Allix et al. [1-4] is modified further to incorporate the friction and sliding effects. The form of the proposed equation for strain energy depends on the experimental results of interfacial problems including friction effects. 


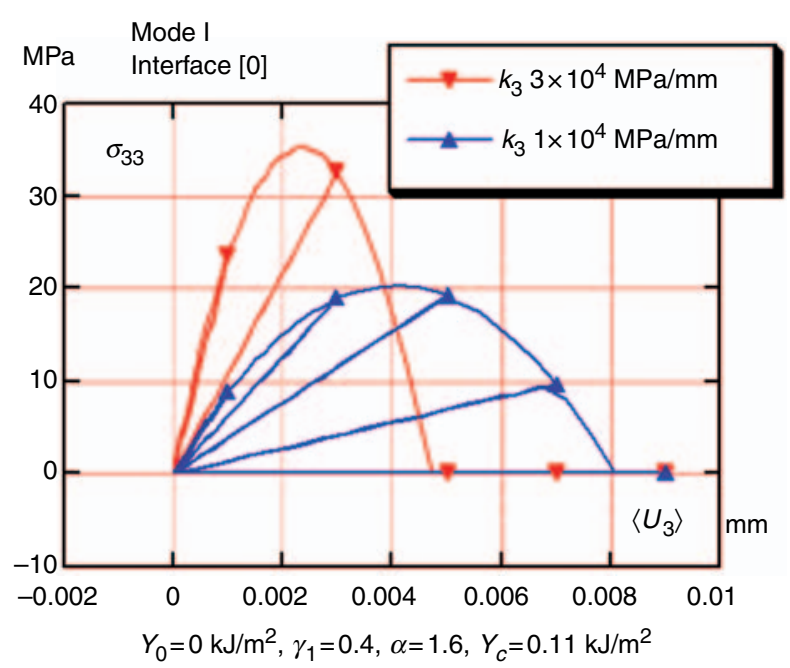

Figure 2. Evolution of stress with displacement.

If $U_{1}^{p}$ and $U_{1}^{e}$ are respectively the sliding and elastic parts of the interface tangential displacements then total tangential displacement $U_{1}$ can be written as $U_{1}=U_{1}^{e}+U_{1}^{p}$ and strain energy can be expressed as:

$$
E_{D}=\frac{1}{2}\left[\left(1-d_{3}\right) k_{3}\left\langle U_{3}\right\rangle_{+}^{2}+k_{3}\left\langle U_{3}\right\rangle_{-}^{2}\right]+\frac{1}{2} k_{1}\left(U_{1}-U_{1}^{p}\right)^{2}+\frac{1}{2} k_{1} \frac{1-d_{1}}{d_{1}}\left(U_{1}^{p}\right)^{2}
$$

Here for simplicity only 2D formulation is considered, because Z-fiber pull-out process requires normal displacement $U_{3}$ and shear displacement $U_{1}$. 3D formulation can also be written by considering sliding and elastic displacements $U_{2}^{p}$ and $U_{2}^{e}$ in Equation (12). Accordingly the relationship between stress and displacement can be written as:

$$
\begin{gathered}
\sigma_{33}=\frac{\partial E_{D}}{\partial U_{3}}=\left[\left(1-d_{3}\right) k_{3}\left\langle U_{3}\right\rangle_{+}+k_{3}\left\langle U_{3}\right\rangle_{-}\right] \\
\sigma_{13}=\frac{\partial E_{D}}{\partial U_{1}}=k_{1}\left(U_{1}-U_{1}^{p}\right)
\end{gathered}
$$

For $\sigma_{13}$, note that the effect of damage parameter $d_{1}$ does not appear directly in the Equation (14), but its influence will be taken into account through inelastic slip $U_{1}^{p}$ variable. Subsequently one can write:

$$
\sigma_{13}^{p}=-\frac{\partial E_{D}}{\partial U_{1}^{p}}=\sigma_{13}-k_{1} \frac{1-d_{1}}{d_{1}}\left(U_{1}^{p}\right)
$$

This is going to play its role in Coulomb friction criterion. The thermodynamic forces associated to damage variables are:

$$
\begin{gathered}
Y_{d_{3}}=-\frac{\partial E_{D}}{\partial d_{3}}=\frac{1}{2} k_{3}\left(U_{3}\right)^{2}, \\
Y_{d_{1}}=-\frac{\partial E_{D}}{\partial d_{1}}=\frac{1}{2} k_{1}\left(\frac{U_{1}^{p}}{d_{1}}\right)^{2} .
\end{gathered}
$$


Energy dissipated in the model can be written as:

$$
\Phi=-\frac{\partial E_{D}}{\partial U_{1}^{p}} \dot{U}_{1}^{p}-\frac{\partial E_{D}}{\partial d_{i}} \dot{d}_{i}=\sigma_{13}^{p} \dot{U}_{1}^{p}-Y_{d_{i}} \dot{d}_{i} \geq 0
$$

where the calculation of evolution of scalar damage variable $d_{i}$ is the same as mentioned in Equations (6)-(8). Coulomb friction law is proposed to govern the inelastic part $U_{1}^{p}$, by introducing the following friction function:

$$
\begin{gathered}
f=\left|\sigma_{13}^{p}\right|-\mu\left\langle\sigma_{33}\right\rangle_{-} \leq 0, \\
f=\left|\sigma_{13}-X_{13}\right|-\mu\left\langle\sigma_{33}\right\rangle_{-} \leq 0, \\
X_{13}=k_{1} \frac{1-d_{1}}{d_{1}}\left(U_{1}^{p}\right),
\end{gathered}
$$

where $\mu$ is the coefficient of friction and $\left\langle\sigma_{33}\right\rangle_{-}$is the normal stress in compression. Here, $X_{13}$ is the kinematic hardening effect which shows an infinite slope at the beginning (when $d=0$ ) and decreasing hardening modulus as damage progresses and finally gives the contact/friction behavior after the complete interfacial failure (when $d=1$ ).

The incremental algorithm for the inelastic interface damage evolution law is based on backward (implicit) Euler method [21], hence one can write for sliding displacement $U_{1 n+1}^{p}$ at time $t_{n+1}=t_{n}+\Delta t$ :

$$
U_{1 n+1}^{p}=U_{1 n}^{p}+\Delta \gamma \operatorname{sign}\left(\sigma_{13 n+1}\right)
$$

where $\Delta \gamma=\dot{\gamma}_{n+1}^{\bullet} \Delta t$ and

$$
\begin{gathered}
\sigma_{13 n+1}=k_{1}\left(U_{1 n+1}+U_{1 n+1}^{p}\right), \\
U_{1 n+1}=U_{1 n}+\Delta U_{1 n} .
\end{gathered}
$$

Similarly one can write:

$$
\begin{gathered}
\sigma_{33 n+1}=k_{3}\left(1-d_{3 n+1}\right)\left\langle U_{3 n+1}\right\rangle_{+}+k_{3}\left\langle U_{3 n+1}\right\rangle_{-}, \\
U_{3 n+1}=U_{3 n}+\Delta U_{3 n} .
\end{gathered}
$$

Now $\sigma_{33 n+1}, \sigma_{13 n+1}$ along with $\Delta \gamma$ are constrained by the discrete version of Kuhn-Tucker conditions:

$$
\left.\begin{array}{l}
f_{n+1}=\left|\sigma_{13 n+1}-k_{1} \frac{1-d_{1 n+1}}{d_{1 n+1}} U_{1 n+1}^{p}\right|-\mu\left|\sigma_{33 n+1}\right\rangle_{-} \leq 0, \\
\Delta \gamma \geq 0, \quad f_{n+1} \leq 0, \quad \Delta \gamma f_{n+1}=0
\end{array}\right\}
$$

The updated inelastic displacement $U_{1 n+1}^{p}$ can be calculated from Equation (22) by using additional Kuhn-Tucker conditions described above [21].

Now consider a case, where damage evolution and sliding at the interface occur simultaneously, that means, $f=0$. Replacing stresses with corresponding displacement discontinuities, from Equation (20):

$$
\frac{U_{1}^{p}}{d_{1}}=U_{1}-\frac{k_{3}}{k_{1}} \mu\left\langle U_{3}\right\rangle_{-} .
$$




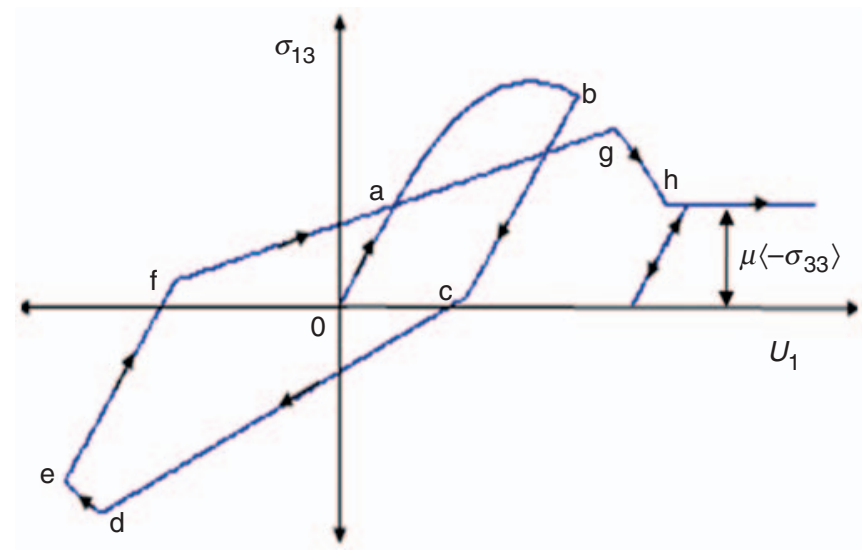

Figure 3. Evolution of stress with shear displacement including friction effects.

Using this relation, Equation (17) can be rewritten as:

$$
Y_{d_{1}}=\frac{1}{2} k_{1}\left(\frac{U_{1}^{p}}{d_{1}}\right)^{2}=\frac{1}{2} k_{1}\left(U_{1}-\frac{k_{3}}{k_{1}} \mu\left\langle U_{3}\right\rangle_{-}\right)^{2} .
$$

A typical response of shear stress and displacement for loading and unloading conditions is shown in Figure 3. Different phases of the response can be explained as:

- 0 - a. During the first loading phase, the interface presents a linear behavior. There is no damage evolution nor does inelastic displacement occur in this phase.

- $a-b$. In this loading phase, Coulomb friction criterion is achieved. One can simultaneously observe the damage evolution and inelastic displacement in this loading phase.

- $b$ - c. An unloading phase follows, characterized by a linear response with the initial stiffness. No damage evolution occurs in this phase.

- $\mathrm{c}-\mathrm{d}$. In this phase negative slip occurs without any damage evolution, hence slope of the curve changes.

- d-e. Damage evolution occurs along with negative slip.

- $\mathrm{e}-\mathrm{f}$. Again a positive reloading is applied which characterizes a linear response with the initial stiffness.

- $\mathrm{f}-\mathrm{g}$. Inelastic slip occurs without any damage evolution.

- $\mathrm{g}-\mathrm{h}$. In this phase damage evolves until the complete debonding of the interface, i.e. the damage variable approaches the value of 1 . After this point interfacial shear stress is only a function of friction.

The above graphical response shown in Figure 3 is for shear stress when the normal stress is of compressive nature. Under tensile loading, the proposed inelastic damage model behaves exactly like classical elastic damage model, [1,2]. Under tensile loading condition, $\sigma_{33}>0$ from relation (20):

$$
\sigma_{13}=k_{1} \frac{1-d_{1}}{d_{1}} U_{1}^{p} \Rightarrow U_{1}^{p}=\frac{d_{1}}{k_{1}\left(1-d_{1}\right)} \sigma_{13}
$$


Substituting the Equation (30) in Equation (14) and after simplification one has:

$$
\sigma_{13}=\left(1-d_{1}\right) k_{1}\left(U_{1}\right) .
$$

This equation for shear stress case is exactly same as the one used in classical elastic damage model. Under tensile condition, Equation (17) will reduce to:

$$
Y_{d_{1}}=\frac{1}{2} k_{1}\left(U_{1}\right)^{2}=\frac{1}{2} \frac{\sigma_{13}^{2}}{k_{1}\left(1-d_{1}\right)^{2}},
$$

which is again thermodynamic force associated to the damage in shear for classical elastic damage model [1,2].

\section{INFLUENCE OF INTERFACIAL PARAMETERS ON INTERFACE BEHAVIOR}

In order to study the influence of different interfacial parameters on the behavior of the proposed interface law, a simple model of linear elements, $1.0 \mathrm{~mm}$ long, bonded through interface is examined. Simulations have been made in finite element software Cast3M [19] using interface element [22,23]. The bottom element is blocked in shear and applying normal compression at the joint (interface) while the upper one is blocked in normal direction and can move in shear direction. A displacement in shear direction is applied, as shown in Figure 4.

The typical response of the friction interface model for different interfacial parameters is given in Figures 5 and 6. In Figure 5, the dependence of interface on $n$ is shown, as we already discussed that higher value of $n$ corresponds to brittle failure for interface, which can also be verified from Figure 5. Figure 6 shows the variation of shear force for different values of normal compressive stress. From the figure it is also clear that under the tensile condition, $\sigma_{33} \geq 0$, the proposed law behaves like classical damage evolution law i.e. under this condition, friction effects are not taken into account.

After the interface is broken there will be only contact with friction, which will play its role to calculate the force till the total contact is finished. The shear stress along the displacement will vary along the length as a function of remaining contact between the two elements. In order to accomplish this, after the debonding is completed, contact parameter $L_{c}$ is introduced here to calculate the final contact-shear stress while all the remaining formulation will be the same:

$$
L_{c}=\frac{\left(L-U_{1 d}\right)-\left(U_{1}-U_{1 d}\right)}{\left(L-U_{1 d}\right)},
$$

where $L$ is the the total length of the $2 \mathrm{D}$ contact surface, $U_{1}$ is the displacement applied in shear direction, $U_{1 d}$ is the displacement value at the instant of complete debonding, when $d_{1}=1$.

The final shear stress will be calculated as:

$$
\begin{aligned}
& \text { if }\left(d_{1} \leq 1 .\right) \\
& \qquad \sigma_{13}^{F}=\sigma_{13} \\
& \text { else } \\
& \qquad \sigma_{13}^{F}=\sigma_{13} \times L_{c} .
\end{aligned}
$$




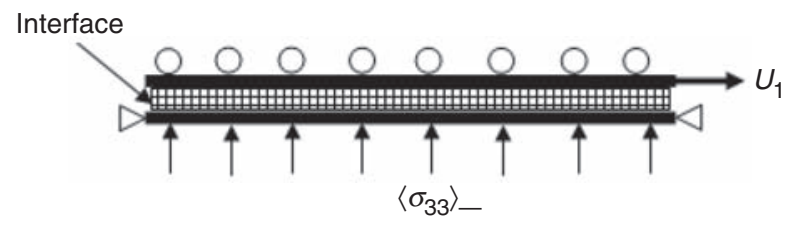

Figure 4. $2 D$ interface element.

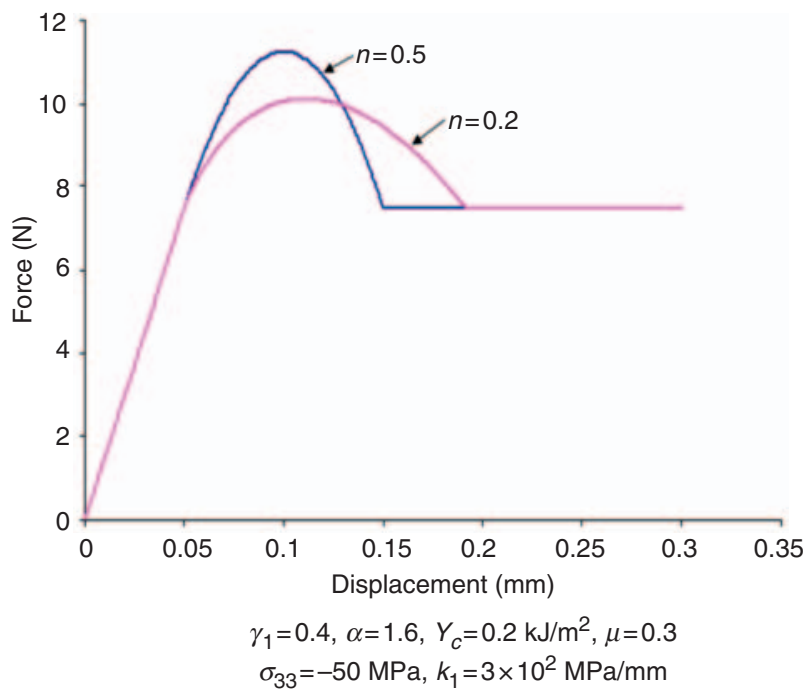

Figure 5. Force displacement curve for $2 D$ interface element with different values of $n$.

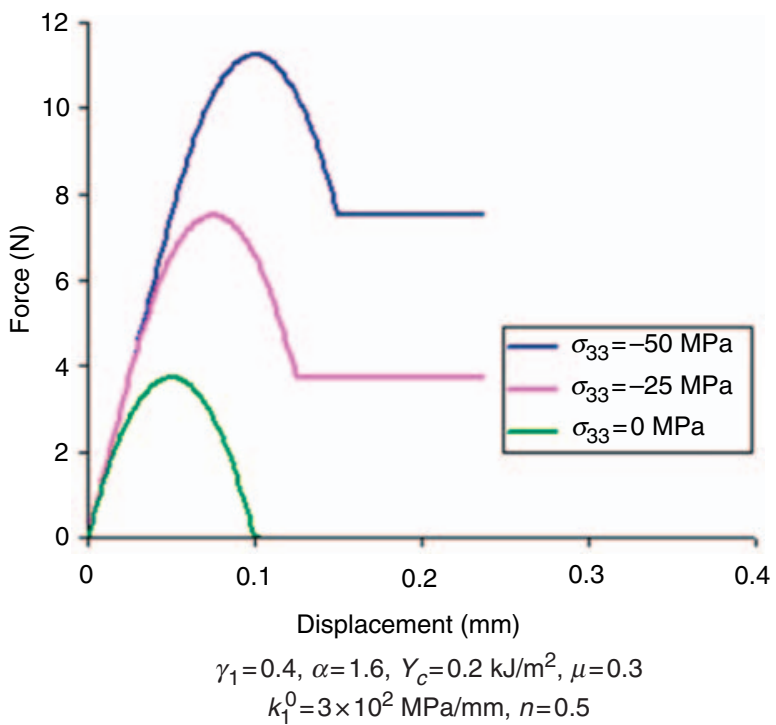

Figure 6. Force displacement curve for $2 D$ interface element with different values of compressive stress. 


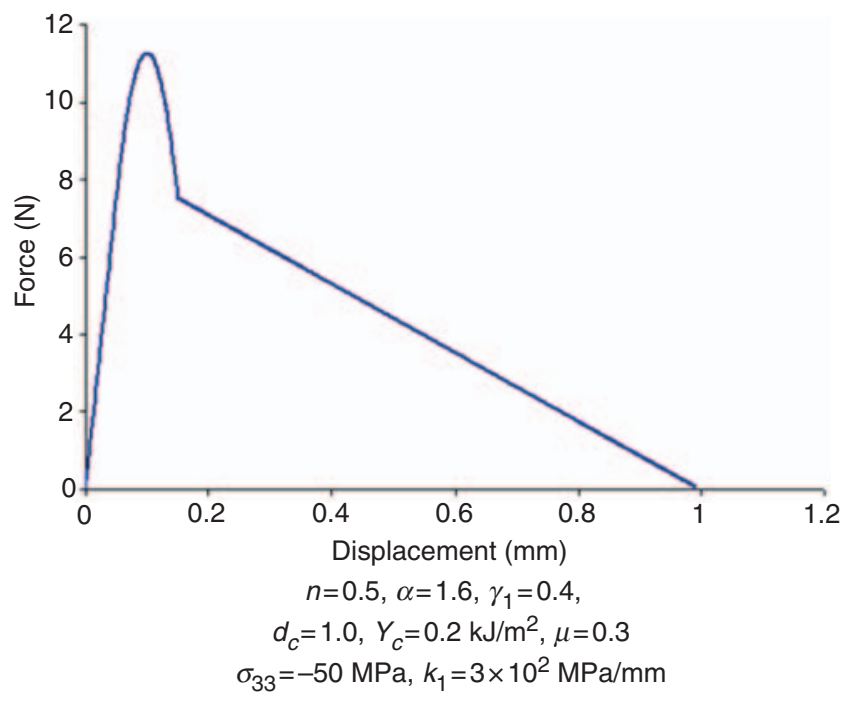

Figure 7. Force displacement curve for $2 D$ interface element.

Here $\sigma_{13}$ the same as calculated from Equation (14) and $L_{c}$ is the contact parameter introduced through Equation (33). The behavior after complete debonding is shown in Figure 7.

In practical problems, when friction is considered, the contact conditions at the interface can also affect the interfacial shear stress. The slip/stick phenomena can occur at the interface between the two adjoining surfaces. However, this effect is neglected here keeping in view the experimental pull-out behavior of Z-fiber [20,24]. During the final pull-out phase, after the interface is completely broken, the pull-out behavior is mostly linear. Most of the experimental results of Z-fiber pull-out also exhibit this type of linear trend [24].

\section{PULL-OUT TEST}

Simulations of two test cases of Z-fiber pull-out are presented in this section. Z-fibers having diameters of 0.51 and $0.28 \mathrm{~mm}$ are inserted into IMS/924 CF/epoxy unidirectional laminate. The material used for Z-fiber is carbon T300/BMI. Experimental observations show that the Z-fiber is getting pulled out from only one half of the laminate, therefore the model is limited to $1.5 \mathrm{~mm}$ long pins [20,24]. Here the assumption is made that the Z-fiber is pulled out from resin-rich area in the laminate, see Figure 9. The radius of the homogeneous resin is taken two times the radius of the pin, this value of radius for resin is selected because higher values do not have significant effect on the final results. The Young's modulus and Poisson's ratio for the isotropic resin material are $3.80 \mathrm{GPa}$ and 0.41 [24]. For Z-fiber the Young's modulus and Poisson's ratio values are 182.2 GPa and 0.28 , respectively [25].

In order to identify the different parameters like critical energy release rate $G_{C}$, which is required to debond the pin from the laminate and residual stress acting at the interface, experimental results of Dai et al. [20] are used. They performed experiments on $3 \times 3 \mathrm{Z}$-fiber samples for small $(0.28 \mathrm{~mm})$ and large $(0.51 \mathrm{~mm})$ diameter pins and then predicted the 


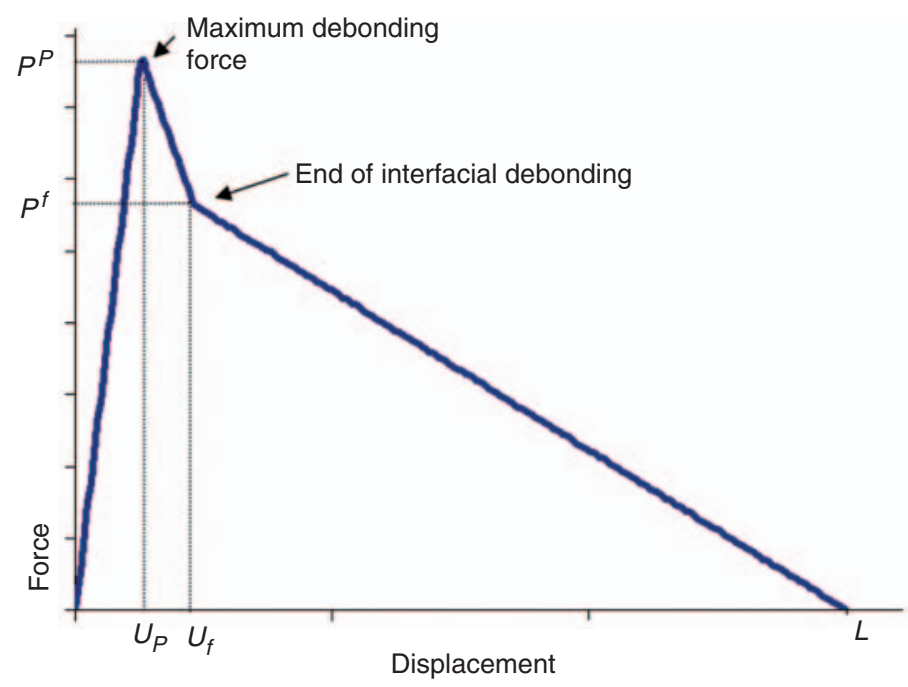

Figure 8. Typical pullout behavior.

behavior of single fiber pull-out. Taking into account the experimental observations, [20,26-28], fiber pull-out behavior can be represented as shown in Figure 8. In Figure 8, load increases with applied displacement till the maximum debonding force, after this point load drops to the point where the debonding of interface is completed. In this phase energy will be consumed partially by interface debonding and partially by frictional sliding. After the total debonding has occurred the slop of the load-displacement curve changes and load will drop to zero as a function of friction and embedded pin length in the laminate. Using Figure 8, area under the curve, from the point of maximum debonding force to the point where debonding is completed is used to estimate the critical energy release rate $G_{C}$. The values of 0.22 and $0.98 \mathrm{~kJ} / \mathrm{m}^{2}$ have been found for critical energy release rate, respectively for single large and small pin pull-out tests by measuring the area under the curve.

Table 1 shows the values of different parameters explained by Figure 8 for small and large diameter pins obtained from experimental results of Dai et al. [20]. If $\sigma_{\text {pin }}$ is the maximum stress experienced by pin due to friction during pull-out process then one can calculate for small pin [20]:

$$
\sigma_{\text {pin }}=\frac{4 p_{f}}{\pi \phi_{p}^{2}}=\frac{4 \times 15.7}{3.142 \times(0.28)^{2}}=255.0 \mathrm{MPa} .
$$

Frictional shear stress $\tau_{f}$ at the interface of pin and laminate is related to $\sigma_{\text {pin }}$ via relation [12]:

$$
\sigma_{\text {pin }}=\frac{4 l \tau_{f}}{\phi_{p}} \Rightarrow \tau_{f}=\frac{\phi_{p} \sigma_{\text {pin }}}{4 l}=\frac{0.28 \times 255.0}{4 \times 1.5}=11.9 \mathrm{MPa} .
$$

By repeating the same procedure for large diameter pin almost same value of friction shear stress is found, that is, $\tau_{f}=12.0 \mathrm{MPa}$. Now $\tau_{f}$ is related to compressive stress, $\sigma_{n}$, at the interface of pin and laminate through relation: $\sigma_{n}=\tau_{f} / \mu$. Using suitable value for coefficient of friction, $\mu=0.4$ [29] one finds compressive stress $\sigma_{n} \approx 30.0 \mathrm{MPa}$. 
Table 1. Maximum debonding and friction force values and corresponding displacements [21].

\begin{tabular}{lcccc}
\hline & $\boldsymbol{P}_{\boldsymbol{d}}(\mathbf{N})$ & $\boldsymbol{P}_{\boldsymbol{f}}(\mathbf{N})$ & $\boldsymbol{U}_{\boldsymbol{d}}(\mathbf{m m})$ & $\boldsymbol{U}_{\boldsymbol{f}}(\mathbf{m m})$ \\
\hline Large diameter pin $\left(\phi_{p}=0.51 \mathrm{~mm}\right)$ & 38.3 & 28.2 & 0.13 & 0.231 \\
Small diameter pin $\left(\phi_{p}=0.28 \mathrm{~mm}\right)$ & 35.3 & 15.7 & 0.037 & 0.17 \\
\hline
\end{tabular}

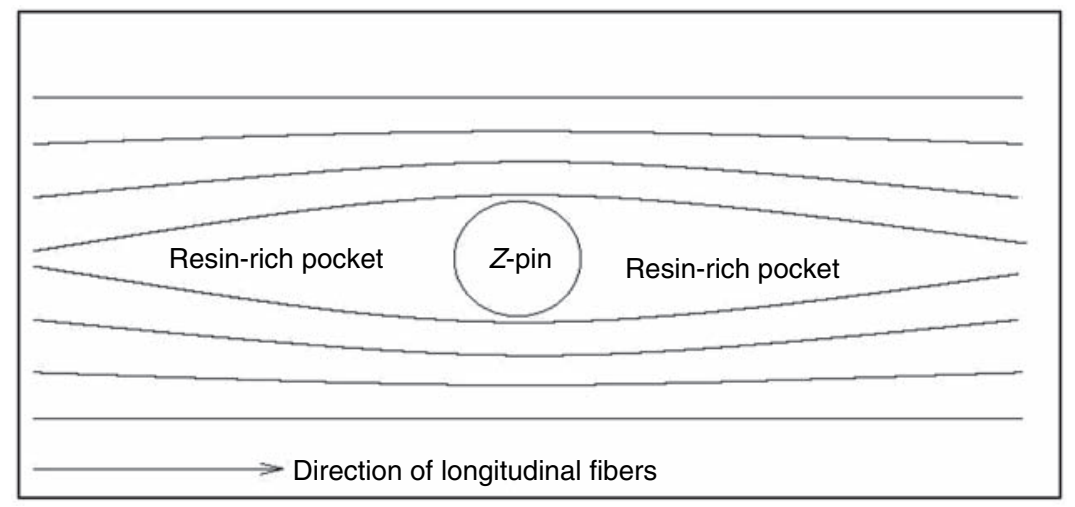

Figure 9. Resin-rich area around the Z-fiber.

This value of normal compressive stress has been used for the single small and large diameter pins pull-out simulations.

The finite element simulation has been made in Cast3M using axis-symmetric plane strain mode condition, Meo et al. [30] also performed pull-out simulation but his method does not include damage mechanics formulation. Two-dimensional four nodes solid quadratic elements (quadrangles) have been used to generate the finite element mesh for Z-fiber and for resin-rich area around the Z-fiber. The interface between the two is modeled by using joint interface element. Figure 9 shows the insertion of Z-fiber in laminate with resin-rich area.

Following are the important parameters should be identified for simulations of pull-out using interface damage law: $\sigma_{n}, \mu, Y_{C}, k_{1}, n, \gamma_{1}, \alpha$. The identification of $\sigma_{n}$ and $\mu$ parameters has already been discussed above. Since pull-out process is taken as pure mode II delamination process hence there is no need to identify $\alpha$, as it vanishes for pure mode case. The value of $Y_{C}$ can be found from identified value of $G_{C}$ by Equation (9). For pure mode II loading condition, one can logically take value of $\gamma_{1}$ equal to 1.0. Thus only $k_{1}$ and $n$ are the significant parameters left to be identified. These two parameters are identified by comparing the simulation results with experimental results for large and small diameter Z-fibers.

The load for the pin pull-out test case is applied in two phases. First, the residual stress has been applied at the interface between resin and Z-fiber and is kept constant for the rest of the calculation. In the second phase, a displacement is imposed on the top of Z-fiber pin till complete pull-out of Z-fiber, as shown in Figure 10. Typical responses for pull-out simulations are shown in Figure 11(a) and (b) for large and small pins, respectively and are compared with experimental results [20]. A good agreement is found between numerical and experimental results in Figure 11. The identified interfacial properties for all the pull-out simulations are given in Table 2. 


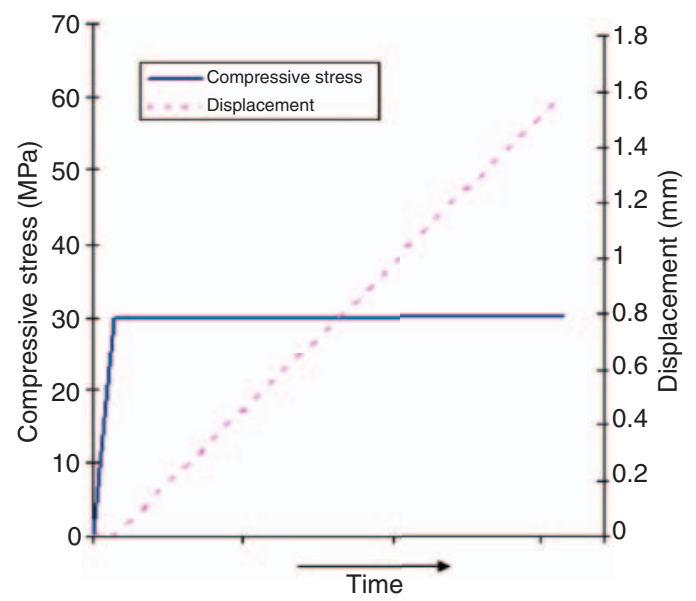

Figure 10. Applied load.
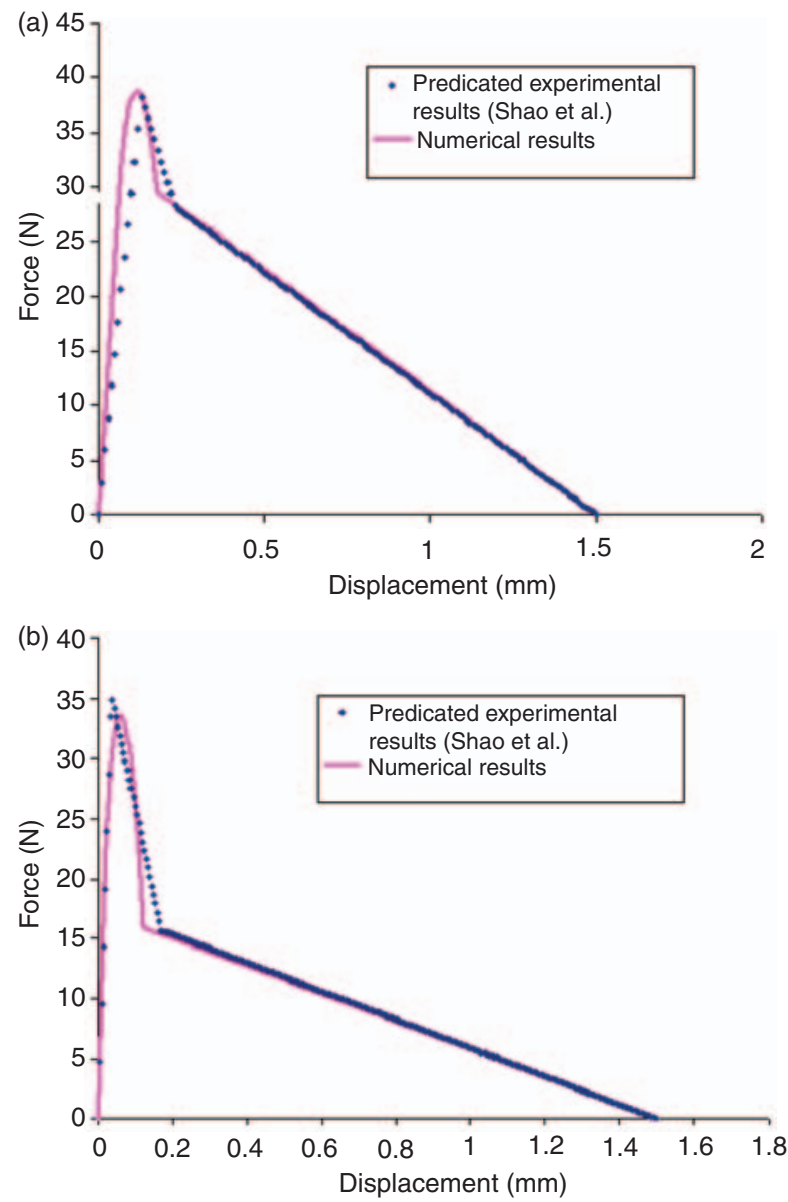

Figure 11. (a) Load-displacement curve for pullout test (pin diameter $0.5 \mathrm{~mm}$ ), (b) load-displacement curve for pullout test (pin diameter $0.28 \mathrm{~mm}$ ). 
Table 2. Interface parameter properties for pullout test.

\begin{tabular}{cccccc}
\hline & $\sigma_{\mathbf{3 3}}(\mathbf{M P a})$ & $\boldsymbol{\mu}$ & $\boldsymbol{Y}_{\boldsymbol{C}}\left(\mathbf{k J} / \mathbf{m}^{\mathbf{2}}\right)$ & $\boldsymbol{n}$ & $\boldsymbol{k}_{\mathbf{1}}(\mathbf{M P a} / \mathbf{m m})$ \\
\hline$\left(\phi_{p}=0.51 \mathrm{~mm}\right)$ & -30.0 & 0.4 & 0.22 & 0.5 & $1.3 \times 10^{2}$ \\
$\left(\phi_{p}=0.28 \mathrm{~mm}\right)$ & -30.0 & 0.4 & 0.98 & 0.5 & $5.0 \times 10^{2}$ \\
\hline
\end{tabular}

\section{CONCLUSION}

In this article, a comprehensive mathematical model of inelastic damage mechanics for interface with friction effects is proposed and implemented in the finite element code Cast3M (CEA). The concept is based on the improved strain energy criterion containing sliding and friction effects. A simple Coulomb friction criterion is used to govern the inelastic sliding with friction during damage evolution. In this model, the evolution of damage variables depends on different interfacial parameters including critical energy release rate as shown with examples in the section 'Influence of Interfacial Parameters on Interface Behavior.' Single Z-fiber pull-out simulations are performed to check the efficiency of proposed inelastic damage model and found to be effective. Five different factors are found to affect the pull-out process. These factors are elastic deformations of Z-fiber and interface, fracture of interface, residual or contact pressure, coefficient of friction and embedded length of Z-fiber in the laminate.

\section{ACKNOWLEDGMENTS}

The authors thank HEC (Higher Education Commission of Pakistan) and its collaborating organisation SFERE (Société française d'exportation des ressources éducatives) for providing financial support.

\section{REFERENCES}

1. Allix, O. and Ladevèze, P. (1992). Interlaminar Interface Modeling for the Prediction of Delamination, Composite Structures, 22(4): 235-242.

2. Allix, O. and Ladevèze, P. (1996). Damage Mechanics of Interfacial Media: Basic Aspects, Identification and Application to Delamination, In: Allen, D.H. and Voyiadjis, G.Z. (eds), Damage and Interfacial Debonding in Composites, Studies in Applied Mechanics 44, pp. 167-188, Elsevier Science B.V., Amsterdam.

3. Allix, O., Ladevèze, P., Gornet, L., Léveque, D. and Perret, L.A. (1998). Computational Damage Mechanics Approach for Laminates: Identification and Comparison with Experimental Results, In: Voyiadjis, G.Z., Ju, J.-W. and Chaboche, J.-L. (eds), Damage Mechanics in Engineering Materials, Studies in Applied Mechanics 46, pp. 481-500, Elsevier Science Ltd, Oxford, U.K.

4. Allix, O., Ladevèze, P. and Corigliano, A. (1995). Damage Analysis of Interlaminar Fracture Specimens, Composite Structures, 31: 61-74.

5. Corigliano, A. and Allix, O. (2000). Some Aspects of Interlaminar Degradation in Composites, Computer Methods in Applied Mechanics and Engineering, 185: 203-224.

6. Corigliano, A. (1993). Formulation, Identification and Use of Interface Models in the Numerical Analysis of Composite Delamination, International Journal of Solids Structures, 30: 2779-2811.

7. Gornet, L. (1996). Simulations des Endommagements et de la Rupture Dans les Composites Stratifies, PhD Thesis, Université Pierre et Marie Curie, Paris 6/LMT/ENS-Cachan.

8. Alfano, G. and Crisfield, M.A. (2001). Finite Element Interface Models for the Delamination Analysis of Laminated Composites: Mechanical and Computational Issue, International Journal for Numerical Methods in Engineering, 50: 1701-1736. 
9. Boutaous, A., Elchikh, M. and Gornet, L. (2007). On the Relevance of the Interface in the Modeling of Damage and Plasticity in Composite Laminates: PEEK/APC2, Composite Interfaces, 14(3): 261-276.

10. Cartié, D.D.R., Trouli, M. and Patridge, I.K. (2006). Delamination of Z-Pinned Carbon Fibre Reinforced Laminates, Composites Science and Technology, 66: 855-861.

11. Cartié, D.D.R. and Partridge, I.K. (1999). Delamination Behaviour of Z-Pinned Laminates, In: Williams, J.G. and Pavan, A. (eds), Proceedings of 2nd ESIS TC4, Les Diablerets, Switzerland, 13-15 September.

12. Tvergaard, V. (1990). Effect of Fibre Debonding in a Whisker-reinforced Metal, Materials Science and Engineering A, 125: 203-213.

13. Alfano, G. and Sacco, E. (2006). Combining Interface Damage and Friction in a Cohesive Zone Model, International Journal for Numerical Methods in Engineering, 68: 542-582.

14. Needleman, A. (1987). A Continuum Model for Void Nucleation by Inclusion Debonding, Journal of Applied Mechanics, 54: 525-531.

15. Chaboche, J.L., Girard, R. and Levasseur, P. (1997). On the Interface Debonding Models, International Journal of Damage Mechanics, 6: 220-257.

16. Chaboche, J.L., Girard, R. and Schaff, A. (1997). Numerical Analysis of Composites Systems by Using Interphase/Interface Models, Computational Mechanics, 20: 3-11.

17. Lemaitre, J. and Chaboche, J.-L. (2000). Mechanics of Solid Materials, Cambridge University Press, London.

18. Allix, O., Ladevèze, P., Deu, J.F. and Léveque, D. (2000). A Mesomodel for Localization and Damage Computation in Laminates, Computer Methods in Applied Mechanics and Engineering, 183: $105-122$.

19. Verpeaux, P., Charras, T. and Millard, A. (1988). Castem 2000: Une Approche Moderne Du Calcul Des Structures, In: Fouet, J.M., Ladevèze, P. and Ohayon, R. (eds), Proc. Calcul des Structures et Intelligence Artificielle, Pluraris, pp. 227-261. Available at: http:// www-cast3m.cea.fr.

20. Dai, S.-C., Yan, W., Liu, H.-Y. and Mai, Y.-W. (2004). Experimental Study on Z-Pin Bridging Law by Pull-out Test, Composites Science and Technology, 64: 2451-2457.

21. Simo, J.C. and Hughes, T.J.R. (1997). Elasto-plasticity and Viscoplasticity: Computational Aspects, Springer-Verlag, Berlin.

22. Beer, G. (1985). An Isoparametric Joint/Interface Element for Finite Element Analysis, International Journal for Numerical Methods in Engineering, 21: 585-600.

23. Balzani, C. and Wagner, W. (2008). An Interface Element for the Simulation of Delamination in Unidirectional Fiber-reinforced Composite Laminates, Engineering Fracture Mechanics, 75: 2597-2615.

24. Cartié D.D.R. (2000). Effect of Z-Fibres on the Delamination Behaviour of Carbon Fibre/ Epoxy Laminates, PhD Thesis, Cranfield University, U.K.

25. Changliang, Z., Mingfa, R., Zhao Wei, Z. and Haoran, C. (2006). Delamination Prediction of Composite Filament Wound Vessel with Metal Liner under Low Velocity Impact, Composite Structures, 75: 387-392.

26. DiFrancia, C., Ward, T.C. and Claus, R.O. (1996). The Single-fibre Pull-out Test. 1: Review and Interpretation, Composites. Part A, Applied Science and Manufacturing, 27: 597-612.

27. Chua, P.S. and Piggott, M.R. (1985). The Glass Fibre-polymer Interface: I - Theoretical Consideration for Single Fibre Pull-out Tests, Composites Science and Technology, 22: 33-42.

28. Chua, P.S. and Piggott, M.R. (1985). The Glass Fibre-polymer Interface: II - Work of Fracture and Shear Stresses, Composites Science and Technology, 22: 107-119.

29. Liu, H.-Y. and Mai, Y.-W. (2003). Delamination Fracture Mechanics of Composite Laminates with Through-thickness Pinning, Strength, Fracture and Complexity, 1: 139-146.

30. Meo, M., Achard, F. and Grassi, M. (2005). Finite Element Modeling of Bridging Micro-mechanics in Through-thickness Reinforced Composite Laminates, Composite Structures, 71: 383-387. 